\title{
Common Adult Stem Cells in the Human Breast Give Rise to Glandular and Myoepithelial Cell Lineages: A New Cell Biological Concept
}

\author{
Werner Böcker, Roland Moll, Christopher Poremba, Roland Holland, \\ Paul J. van Diest, Peter Dervan, Horst Bürger, Daniel Wai, Raihanatou Ina Diallo, \\ Burkhard Brandt, Hermann Herbst, Ansgar Schmidt, Markus M. Lerch, and \\ Igor B. Buchwallow
}

Institute of Pathology (WB, CP, HB, DW, RID, HH), University of Münster, Münster; Institute of Pathology (RM, AS), Philipps University of Marburg, Marburg, Germany; National Expert \& Training Centre for Breast Cancer Screening $(R H)$, Academisch Ziekenhuis Nijmegen, Nijmegen; Department of Pathology (PJvD), Free University Hospital, Amsterdam, The Netherlands; Pathology Department (PD), University College Dublin, Mater Hospital, Dublin, Ireland; Institute of Clinical Chemistry and Laboratory Medicine (BB), Münster; and Department of Medicine B and Central Ultrastructure Research Unit (MML, IBB), Interdisciplinary Center of Clinical Research, University of Münster, Münster, Germany

SUMMARY: Breast biology and pathology are currently shaped by the two-cell concept that recognizes only glandular and myoepithelial cells. In the present study, we have visualized a previously unidentified cell population within the epithelial compartment of the breast, which displays the phenotypic characteristics of a committed stem cell. Immunofluorescence double labeling with digital image processing and Western blotting were applied to normal breast tissue as well as to noninvasive and invasive breast cancers using antibodies to basal cytokeratin 5 (Ck5), glandular cytokeratins 8/18 (Ck8/18/19), and smooth muscle $\alpha$-actin (SMA) as markers for myoepithelial cells (SMA). A distinct population of cells was identified that expressed Ck5 in the absence of Ck8/18/19 or SMA. These cells differentiate toward glandular epithelial or myoepithelial Ck5-negative end cells passing through either $\mathrm{Ck} 5 / \mathrm{Ck} 8 / 18 / 19$ or $\mathrm{Ck} 5 / \mathrm{SMA}$-positive intermediates. Our experiments clearly demonstrate a precursor or committed stem cell function of the $\mathrm{Ck} 5$-positive cell that is responsible for regeneration of the human adult breast epithelium. However, the observation that the vast majority of breast cancers display the glandular epithelial immunophenotype strongly suggests that the neoplastic cells derive from a late stage of the glandular epithelial differentiation pathway. The significance of this new cell biological model is that it might serve as a tool to unravel the regulatory mechanisms that govern regeneration and abnormal proliferation of breast epithelium at the cellular level. (Lab Invest 2002, 82:737-745).

$T$ he current system in the "descriptive set theory" distinguishes two principal differentiated cell types within the human mammary gland epithelium: the inner glandular and the outer myoepithelial cells, which are characterized by expression of glandular cytokeratins (Ck) 8/18/19 or smooth muscle actin (SMA), respectively (Taylor-Papadimitriou et al, 1991). The question of whether stem cells exist in the human breast has never been satisfactorily resolved, although immunohistochemical and cell proliferation analyses (Dulbecco et al, 1986; Joshi et al, 1986; Purkis et al, 1990; Taylor-Papadimitriou et al, 1991), developmen-

DOI: 10.1097/01.LAB.0000017371.72714.C5

Received December 29, 2001.

This study was supported by Deutsche Krebshilfe; 10-1681-Bü-I.

Address reprint requests to: Dr. Werner Boecker, Professor of Pathology, Gerhard Domagk-Institute of Pathology, Domagkstrasse 17, D-48149

Münster, Germany.E-mail: boeckew@uni-muenster.de tal (Sonnenberg et al, 1986), single breast cell transplantation (Kordon and Smith, 1998), and recent molecular studies (Lakhani and O'Hare, 2001; O'Connell et al, 1994) gave indirect evidence of the existence of stem cells in murine and human breast tissue.

Using a double-fluorescence method with antibodies specific for Ck5/6, Ck8/18/19/19, and SMA, as well as Western blotting techniques, we studied the relationship between Ck5-positive cells and Ck8/18/19positive glandular epithelial as well as SMAexpressing myoepithelial cells in normal human breast tissue and in breast cancer. Our results indicate that Ck5-positive cells represent progenitor cells, ie, committed stem cells, for both the glandular and myoepithelial lineages of mammary epithelium. Except in some rare cases, breast cancer shows a purely glandular phenotype. The direct visualization of cellular subpopulations, in connection with molecular studies, will aid dissecting the hierarchies of cell types and their interplay in normal breast tissue and proliferative breast disease and, thus, may help in designing new 
therapeutic concepts targeting cancer precursors at distinct levels of differentiation.

\section{Results}

\section{Double Immunofluorescence Staining Experiments: Normal Nonlactating and Lactating Breast Tissue}

CK5-positive cells differentiate to glandular epithelial and myoepithelial cells via intermediary cells. Double staining of eight normal breast tissues with antibodies against either Ck5 and Ck8/18/19 or SMA displayed variable, but usually small, proportions of cells characterized by exclusive expression of Ck5. These exclusively Ck5-positive cells, accounting for less than $5 \%$ of the whole cell population, were individually dispersed largely throughout the inner layer of the ductal system. In normal breast lobules, their distribution was irregular.

Cells expressing only Ck8/18/19 or SMA, corresponding to fully differentiated glandular and myoepithelial cells, respectively, were more numerous. Notably, intermediary or transitory cells with coexpression of either Ck5 and Ck8/18/19 or Ck5 and SMA were most abundant in the ductal system and, again, irregularly distributed in the lobular system (Fig. 1). Such intermediary glandular cells (Ck5+; Ck8/18/19+) were found in the inner cell layer, and intermediary myoepithelial cells $(\mathrm{Ck} 5+, \mathrm{SMA}+)$ in the outer layer, thus indicating transitions of Ck5-positive cells to either differentiated glandular or myoepithelial cells.

In lactating mammary gland tissue, however, luminal cells of lobules showed virtually exclusive immunostaining for Ck8/18/19, whereas Ck5-positive luminal cells and transitional glandular cells (Ck5+; Ck8/ $18 / 19+$ ) were absent. In contrast, interlobular and terminal ducts of the lactating gland revealed the same Ck5+ and Ck8/18/19+ staining pattern as seen in the nonlactating gland (Figs. 1 and 2).

\section{Double Immunofluorescence Staining Experiments: Noninvasive and Invasive Breast Cancer}

Breast cancer cells usually display a glandular epithelial phenotype. Sixteen out of 17 invasive breast cancers (IBCs) (eight invasive ductal of different grades; three tubular, all grade 1; two mucinous, grade 1; four lobular, classical type, grades 1 and 2) displayed the same characteristic Ck8/18/19+ and Ck5-immunoprofile of the tumor cells. The same pattern was observed in 15 cases of ductal carcinoma in situ (DCIS) of varying grades ( $n=4$, low nuclear grade; $n=6$, intermediate nuclear grade; and 5 of 6 , high nuclear grade) and in three lobular neoplasias. All of these lesions displayed exclusive Ck8/18/19 expression in the neoplastic cell population (Fig. 3). Thus, transitions from Ck5+ progenitor cells to Ck8/18/19+ glandular cells were absent. Double staining for $\mathrm{Ck} 5$ and SMA showed a mixture of intermediary myoepithelial $(\mathrm{Ck} 5+, \mathrm{SMA}+)$ and myoepithelial end cells (SMA+;Ck5-) with only occasional Ck5+ and SMAcells in the outer cell layer, thus indicating a normal basal layer. Tumor cells coexpressing Ck5 and Ck8/18/19 were found in only two of the 38 cases of breast cancer, one representing a DCIS of high nuclear grade, the other one a grade 3 invasive ductal carcinoma (not shown).

\section{Western Blotting Experiments}

To corroborate the double-labeling immunofluorescence data, breast tissue samples were subjected to Western blotting analysis. For electrophoretic separation of polypeptides, the lesions were microdissected. Using mAbs against Ck5 and Ck8, distinct signals were observed in normal breast tissue, such as a 58 kDa-band corresponding to the basal keratin Ck5 (Fig. 4, lane 3) and a similar signal on a $52.5 \mathrm{kDa}$ band corresponding to the glandular keratin Ck8. In DCIS, a strong signal was only detected at the Ck8 band, whereas a Ck5-specifc band was visible as a faint signal, most probably corresponding to the nonneoplastic basal layer (Fig. 4, lane 4). Western blotting using monoclonal mAb Ck5/6 and mAb Ck8 revealed the expected results in control cells with established keratin composition, ie, presence of $\mathrm{Ck} 5$ and of Ck8 in A-431 cells and the presence of Ck8 in A-549 cells (Fig. 4, lanes 1 and 2). The data provide biochemical proof of the specificity of the Ck5 antibody, thus corroborating the immunofluorescence data.

\section{Discussion}

Using double immunolabeling with digital image processing for simultaneous demonstration of the basal Ck5 and the lineage-specific differentiation markers Ck8/18/19 and SMA, we provided morphologic evidence for the presence of a solely Ck5-positive cell population fulfilling the morphologic requirements to be addressed as a committed stem cell for the epithelial compartment of normal breast tissue. We also provided morphologic proof of the capacity of Ck5+ cells to differentiate to glandular $(\mathrm{Ck} 8 / 18 / 19+)$ or to myoepithelial cells (SMA + ), respectively (see Fig. 5), through intermediary cells. Over the course of the lineage-specific differentiation process there is a gradual decrease of $\mathrm{Ck} 5$ along with an increase in either Ck8/18/19 in the glandular or in SMA in the myoepithelial cell lineages. Terminally differentiated end cells were characterized by expression of either Ck8/18/19 or SMA alone. Our data indicate that commitment to either one of the lineages involves suppression of the alternative lineage choice. We were not able to confirm recent in vitro observations regarding a phenotypic plasticity of "luminal" epithelial cells with transdifferentiation to myoepithelial ones (Pechoux et al, 1999; Peterson et al, 2001).

When microdissected and subjected to Western blotting analysis, normal breast tissue displayed expression of both Ck5 and Ck18. In the present study, a monoclonal antibody described as specific for both Ck5 and Ck6 was used whose specificity in breast tissue for Ck5, but not Ck6, was established by Western blotting, thus further sustaining our concept in biochemical terms. The data are in accordance with previous results obtained by two-dimensional gel 

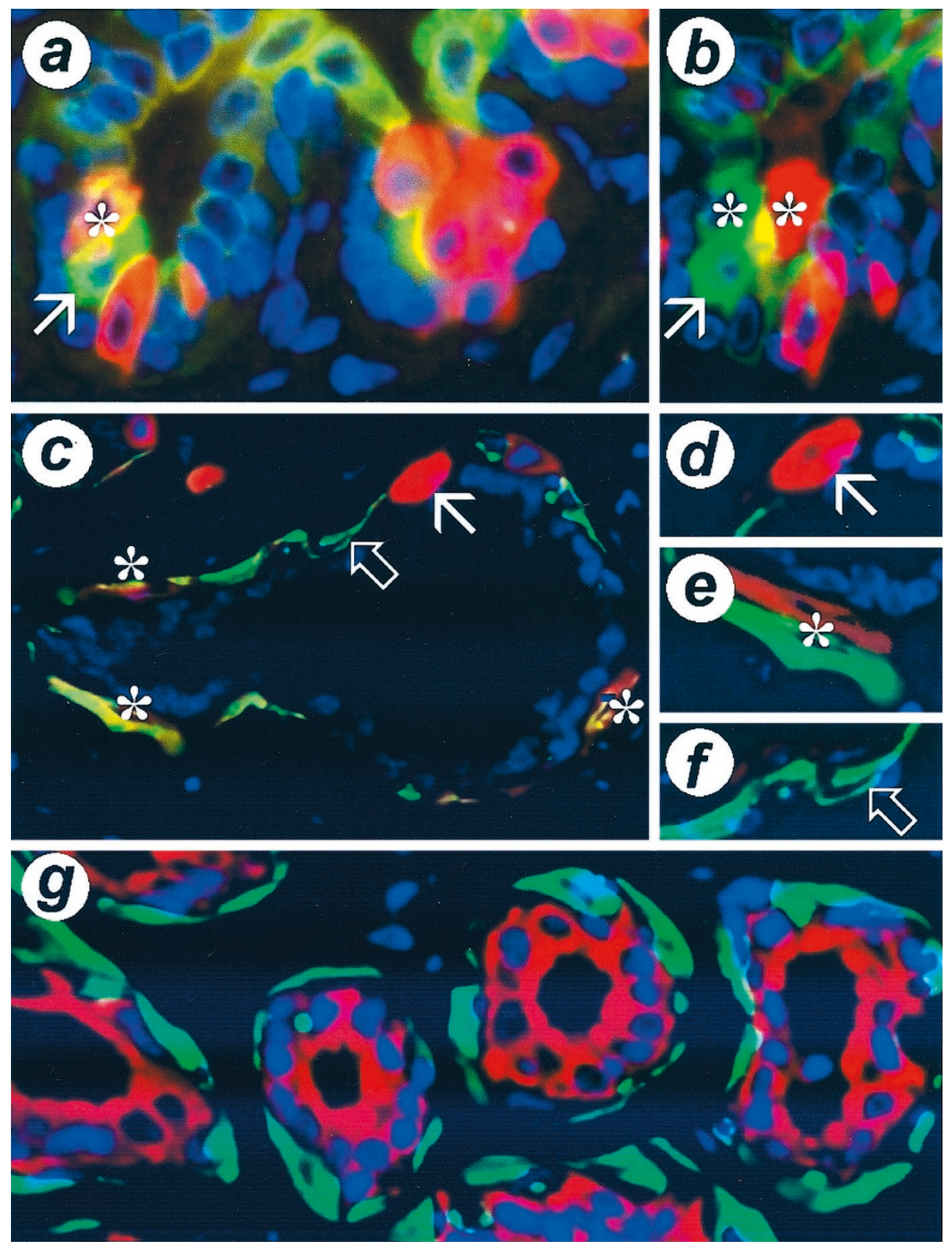

\section{Figure 1.}

Digital image processing fluorescence double immunolabeling enables the simultaneous detection of two different antigens in the same cell and gives evidence that progenitor cells of the breast give rise to both glandular and myoepithelial cells. a, Double immunolabeling of two acinar structures of a lobule for Ck5/6 (green signal for FITC) and Ck8/18/19 (red signal for Cy3) displaying Ck5/6+ progenitor cells (arrow), intermediary cells (asterisk), and Ck8/18/19+ glandular cells (red signal). b, The left part of figure 1a with a 57-pixel shift of the red component to the right, revealing a coincidence of the green and red signal in the intermediary glandular cell marked with an asterisk. c, Double immunolabeling for Ck5/6 (red signal) and smooth muscle actin (SMA) (green signal). The arrow marks a progenitor cell expressing Ck5/6 alone. Intermediary myoepithelial cells expressing both Ck5/6 and SMA are marked with an asterisk. The differentiated myoepithelial end cell is indicated by a hollow arrow. Panels $\mathrm{d}$, e, and f display single cells of the composite image in panel $\mathrm{c}$ with a 31-pixel shift of the red signal upward. Note that only the intermediary cell in panel e expresses both Ck5/6 and SMA. g, Double immunolabeling for SMA (green) and Ck8/18/19 (red) clearly shows a glandular and myoepithelial cell lineage. Note the absence of any transitional cells, indicating that there is no transdifferentiation between those two lineages.

electrophoresis, which showed that the keratin pattern of normal breast tissue comprises Ck7, Ck8, Ck18, and Ck19 in addition to Ck5, Ck14, Ck15, and Ck17, but not Ck6 (Moll, 1998). We, therefore, assume that Ck5 is the predominant type II keratin of progenitor cells that is detected by the Ck5/6 mAb used. In view of the results obtained, we conclude that Ck14 and
Ck17 represent the major type I partners of Ck5 (Cooper et al, 1985; Nagle et al, 1986). Also, recently published gene expression data in normal breast tissue and in breast cancer show gene-expression patterns to be characteristic of "basal" and "luminal" phenotypes (Perou et al, 2000). The correspondences between these gene expression data and our immu- 

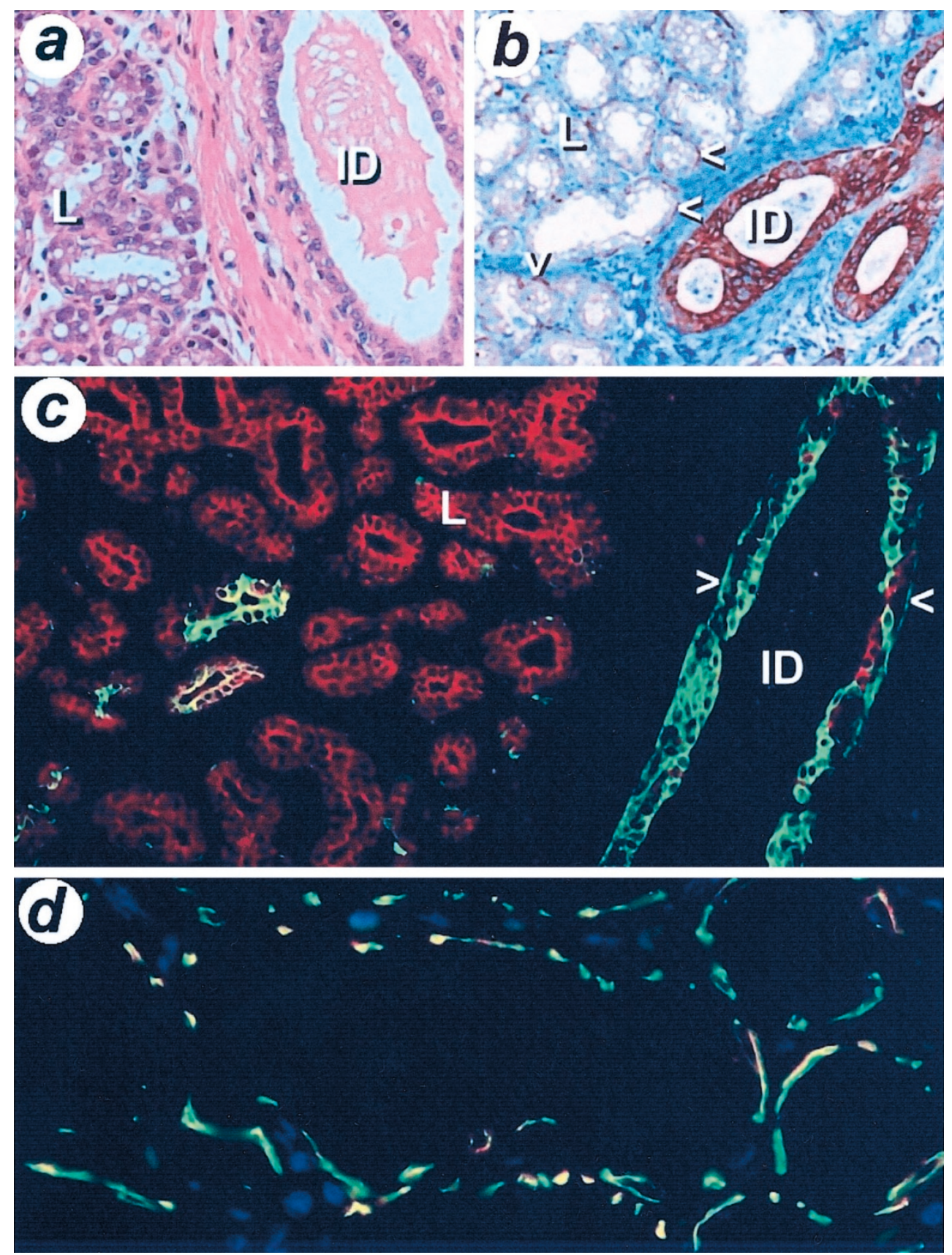

Figure 2.

Lactating mammary gland. Hematoxylin-eosin stained section (a), HRP-immunohistochemical labeling of K5 (b), and double immunolabeling of paraffin-embedded tissues, stained with AB to keratin subgroups Ck5 (green) and Ck8/18/19 (red) (c), and Ck5 (red) and SMA (green) (d). a, Small interlobular duct (ID) and a part of a lactating lobule (L). b, HRP-immunohistochemical labeling of Ck5 of an interlobular duct (ID) and adjacent lactating lobule (L) reveals a heterogeneous staining pattern. Note the negative reaction of the glandular epithelium of the acini. Some basal cells of acini are weakly stained (arrowheads). c, Double labeling for K5 and K8/18 of an interlobular duct (ID) and of a lactating lobule (L). The lactating lobule contains fully differentiated lactating cells, expressing Ck8/18/19 alone (red). Only the intralobular terminal duct contains $\mathrm{Ck} 5+$ luminal cells (green) and some $\mathrm{Ck} 5+, \mathrm{Ck} 8 / 18 / 19+$ intermediary cells (hybrid yellow color). At low magnification the attenuated basal (myoepithelial) cells can hardly be seen. The myoepithelial cell layer of the interlobular duct also stains for Ck5 (arrowheads). d, Double labeling for Ck5 and SMA of lactating acini. Notice that luminal cells are not stained. The outer layer contains Ck5+/SMA+ intermediary myoepithelial cells (hybrid yellow color) and SMA+ differentiated myoepithelial end cells (green signal).

nofluorescence findings are also strong evidence for our stem cell concept. Based on our immunofluorescence and biochemical data, we propose the concept as it is depicted in Figure 5. Thus, normal breast tissue is assumed to consist of the following five distinct cell populations (Fig. 5): (1) committed stem (progenitor) cells $(\mathrm{Ck} 5+)$, (2) glandular precursor cells $(\mathrm{Ck} 5+/ \mathrm{Ck}$
8/18/19+), (3) glandular end cells $(\mathrm{Ck} 8 / 18 / 19+)$, (4) myoepithelial precursor cells (Ck 5/6+/SMA + ), and (5) myoepithelial end cells (SMA + ).

The hypothesis of a stem cell function of the Ck5positive cells and hierarchical organization of the differentiation process is further supported by the compartmentalization of the epithelial structures into a 

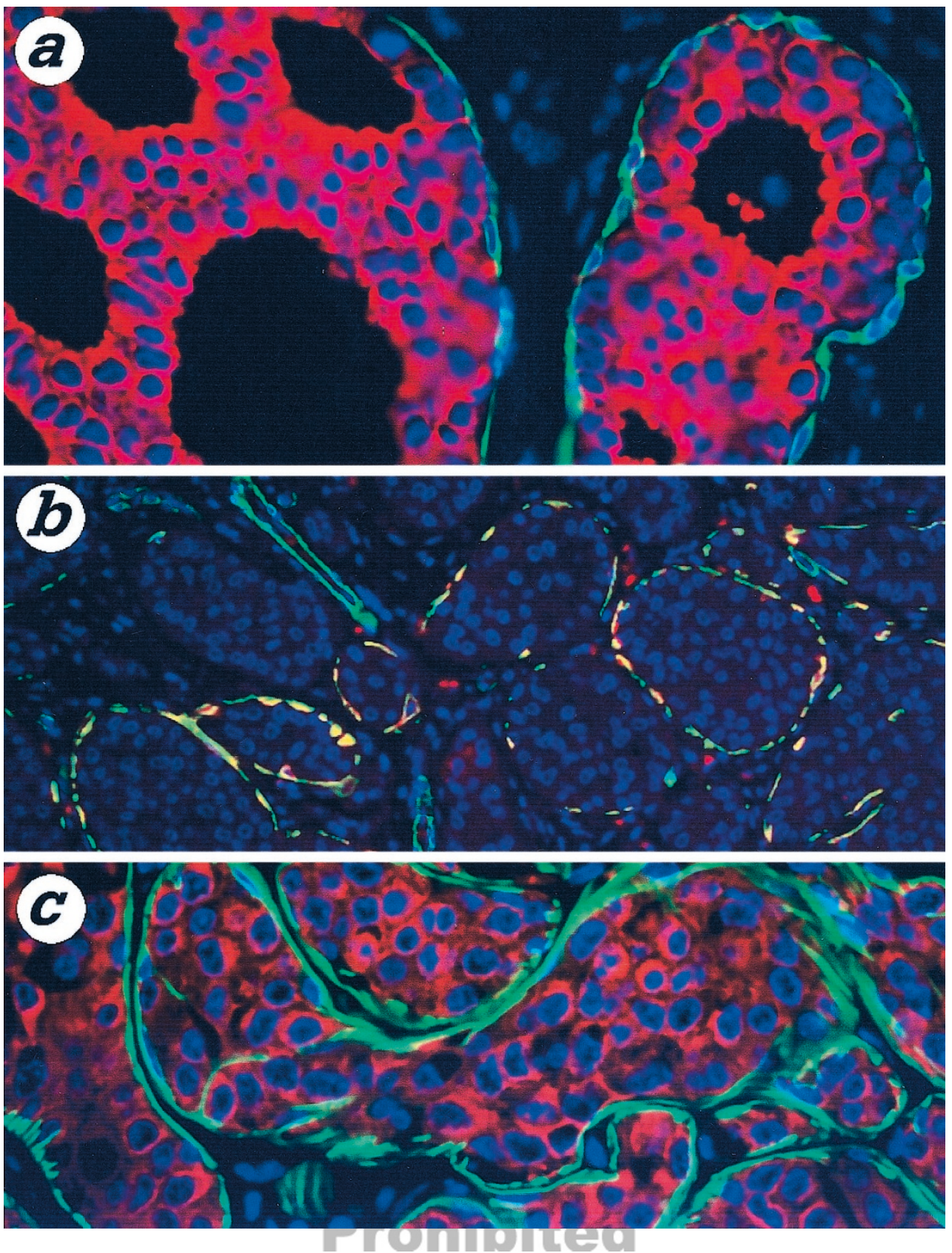

Figure 3.

Ductal carcinoma in situ is a glandularly derived lesion. a, Double immunolabeling for Ck5/6 (green signal) and Ck8/18/19 (red signal) showing that the tumor cells only express Ck8/18/19. b, Double immunolabeling for Ck5/6 (red signal) and SMA (green signal). The outer cell layer consists of normal myoepithelial cell lineage. Note only occasional progenitor cells (red signal), many intermediary cells (hybrid signal), and some differentiated myoepithelial cells (green signal). The neoplastic cells do not express Ck5/6. c, Double immunolabeling for SMA (green signal) and Ck8/18/19 (red signal).

functional and proliferative zone in the lactating mammary gland. Under those conditions, the lobules harbor only Ck8/18/19-positive terminally differentiated lactating end cells, whereas the terminal ducts remain an important proliferative zone characterized by the presence of committed stem and glandular precursor cells. This compartmentalization seems to be a prerequisite of postlactational involution. The cellular mechanisms of this process are currently not understood (Anderson et al, 1982). In any case, it is thought that all of the lactating cells ultimately undergo apoptosis and, therefore, have to be replaced. We believe that a subset of progenitor and/or glandular precursor cells located in the terminal ducts may be instrumental for the repopulation of the lobular compartments and may thus contribute to the remodeling process referred to as postlactational involution.

An important implication of our study is that there are different types of breast cancer, which can be distinguished by their cytokeratin expression patterns. The large majority of cases $(>95 \%)$ show a purely glandular phenotype (Ck5-/Ck8/18/19+) with only a small proportion displaying a glandular precursor phenotype $(\mathrm{Ck} 5+/ \mathrm{Ck} 8 / 18 / 19+)$. Carcinomas with a pure 


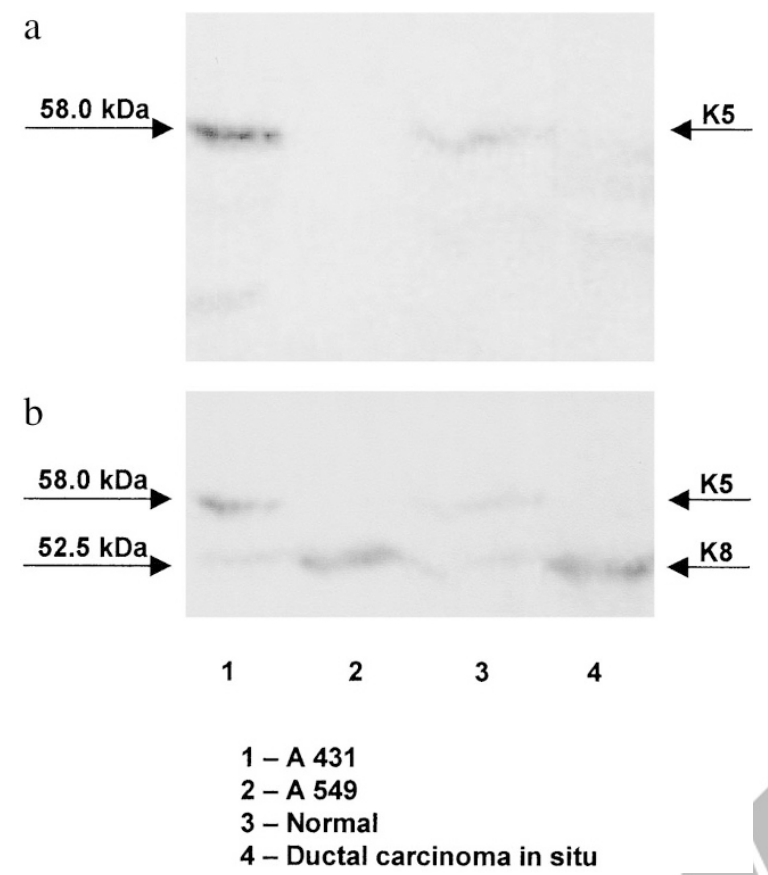

Figure 4.

Western blotting of breast tissue preparations and cultured cells. Lane 1, A-431 cells (total cellular proteins); lane 2, A-549 cells (total cellular proteins); lane 3, normal breast tissue (microdissected terminal ducts and lobular units); lane 4, ductal carcinoma in situ (DCIS) (microdissected ductal lesions). a, Western blotting reaction produced by monoclonal $\mathrm{mAb} C \mathrm{Ck} 5 / 6$. Only a very faint Ck5 reaction is seen for DCIS (lane 4). As expected, clear-cut Ck5 bands are present in normal breast tissue (lane 3) and A-431 cells (lane 1). b, Subsequent Western blotting immunoreaction with anti-Ck8 after incubation with mAb M20 against Ck8. Note the additional appearance of Ck8 bands (arrowhead; $52.5 \mathrm{kDa}$ ) in all preparations (lanes 1-4). The Ck5 bands, corresponding to the first blot reaction, are also visible.

stem cell phenotype (Ck5+/Ck8/18/19-/SMA-) and malignancies of myoepithelial type are exceptionally rare (Lakhani and O'Hare, 2001). This data is in good agreement with cell culture studies showing Ck5 mRNA and protein to be expressed in normal mammary epithelial cells and to be absent from tumorderived cell lines (Trask et al, 1990). Furthermore, many breast cancers are oestrogen receptor-positive, as are the Ck8/18/19+ glandular cells. (Allred and Mohsin, 2001; Clarke et al, 1997; Elston and Ellis, 1989; Kelsey et al, 1993; Shoker et al, 2000; Willett et al, 2001).

In conclusion, we present direct evidence that Ck5positive cells display stem cell properties and are capable of forming glandular epithelial and myoepithelial end cells. This cell model opens a new field in which distinct cell subtypes are being evaluated to generate lineage-specific end cells. We have begun to draw possible functional links between the different subsets of cells in terms of receptor expression profiles. If we were to understand the regulatory mechanisms that govern the growth and differentiation (Siziopikou and Schnitt, 2000), or even elimination of "superfluous cells," as it occurs during the normal menstrual cycle and after weaning, we might be able to design strategies of chemoprevention to eradicate early transformed cells (Dooley et al, 2001) or even cells of noninvasive breast cancer.

\section{Materials and Methods}

\section{Tissues}

Mammary tissue biopsy materials were obtained from 36 women (aged 32 to 71 years, median 55 years). The procedure for the use of human tissue from surgical pathology was approved by the institutional review board and performed in accordance with the ethical standards of the regional committee on human studies.

The lesions were diagnosed on routinely hematoxylinand eosin-stained sections and diagnosed independently by three pathologists according to current classification schemes (Elston and Ellis, 1989; Holland et al, 1994; Page and Anderson, 1987; Silverstein et al, 1995; Sloane, 2001). Eight samples obtained from seven patients consisted of normal breast tissue (five premenopausal and two postmenopausal), 10 samples of DCIS, 17 of IBC of different subtypes with seven associated DCIS (total of 17 DCIS: five low nuclear grade, five intermediate nuclear grade, and seven high nuclear grade), and three lobular carcinoma in situ.

\section{Antibodies and Immunohistochemical Staining}

For antigen retrieval, dewaxed and rehydrated sections cut from routine paraffin blocks after formaldehyde fixation were autoclaved in citrate buffer, $\mathrm{pH} 6.0$, at $120^{\circ} \mathrm{C}$ for 10 minutes for antigen retrieval. Thereafter, sections were rinsed with Tris- $\mathrm{HCl}$ buffer, $\mathrm{pH}$ 7.6. Tris buffer was used for all washing steps. Sections were incubated 45 minutes at room temperature with primary monoclonal mouse antibodies specific for Ck5 (clone D5/16B4; Zymed, San Francisco, California, diluted 1:50; and Dako, Hamburg, Germany, diluted 1:80), Ck8/18 (used as a cocktail of Ck8 and Ck18; clones C 51 and DC 10, diluted 1:10 and 1:20, respectively; Quartett, Berlin, Germany), Ck8/18/19 (clone KL1; Immunotech, Marseille, France, diluted 1:50), and SMA (clone 1A4; Sigma, Taufkirchen, Germany, diluted 1:200). In this study, the systematic use of Abs to Cks8/18 and 8/18/19 revealed the same results, which is why we prefer resorting the $A b$ to $a$ broader spectrum of glandular Cks. All Abs were diluted in 10\% RPMI (Sigma) complemented with 10\% BSA (Sigma) and $0.1 \% \mathrm{NaN}_{3}, \mathrm{pH} 7.5$. For simultaneous demonstration of pairs of mAbs, the following strategy was used. After visualization of a first primary monoclonal mAb with FITC-conjugated rabbit-antimouse antibody (Dianova, Hamburg, Germany, diluted 1:50), sections were immunoreacted with the second primary monoclonal mAb, which we biotinylated using the DAKO ARK biotinylating kit (Dako). The biotin label was consequently visualized with Cy3conjugated streptavidin (Dianova, 1:500). The SMA $\mathrm{mAb}$ was used as a FITC conjugate. Finally, nuclei were counterstained with diamidino-2-phenylindole (DAPI) (Sigma, $5 \mu \mathrm{g} / \mathrm{ml}$ Tris buffer) for 15 seconds. Controls were incubated without primary $\mathrm{mAb}$ or replacing of the primary $m A b$ with mouse IgG applied 


\section{Hypothetical progenitor (adult stem) cell concept}

\section{Breast cancer Ck 5 positive}

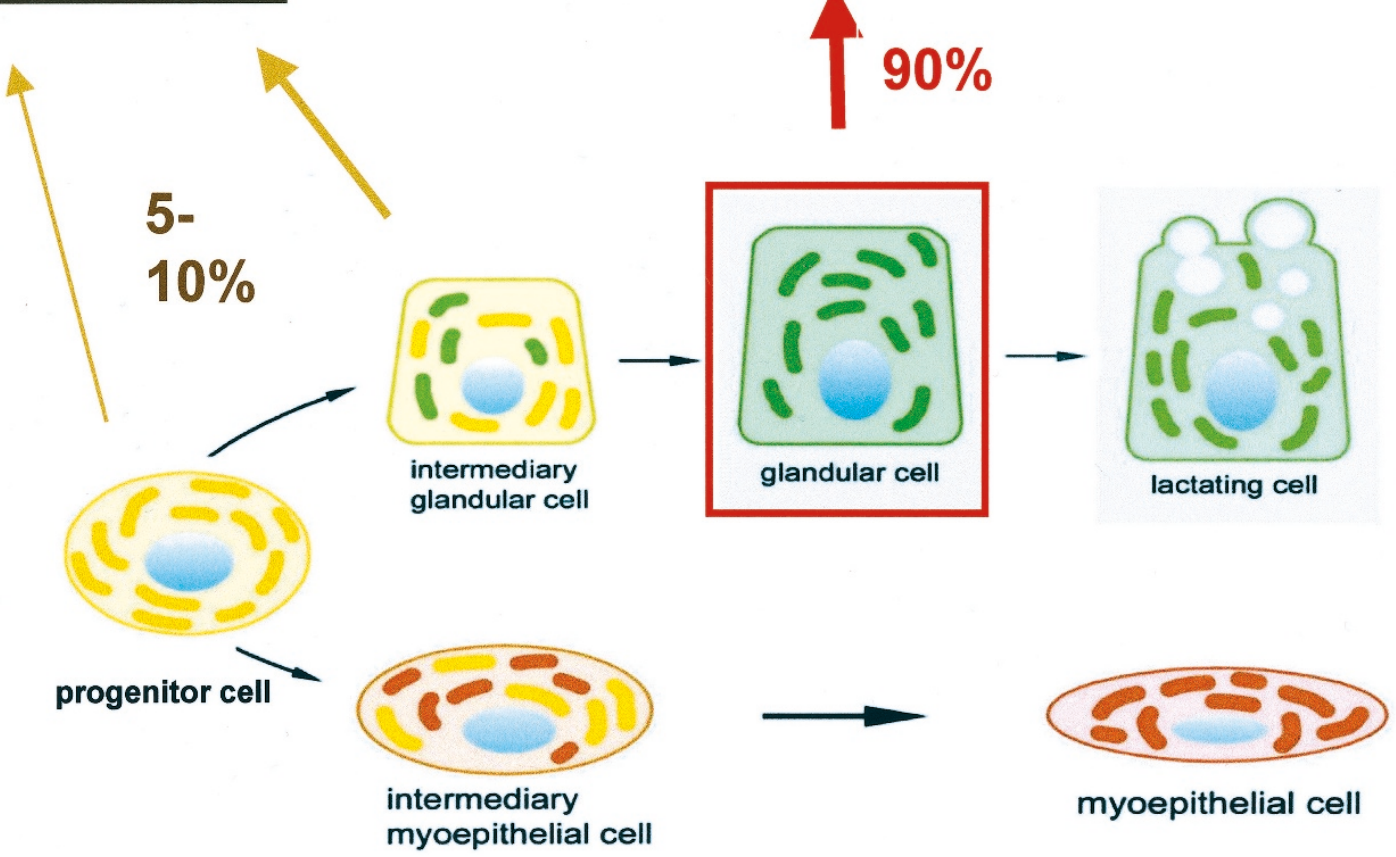

Figure 5.

A new cell biology concept based on our fluorescence immunolabeling and Western blot findings, complemented by gene expression studies from the literature. Ck5+ progenitor cells (yellow) give rise to both glandular cells (Ck8/18/19+; green) and myoepithelial cells (SMA+; red) via intermediary cells, which c0-express Ck5/6 with the lineage-specific marker (either Ck8/18/19+ or SMA+). This model describes the fundamental cellular differences between benign proliferative breast lesions and most types of breast cancer.

at the same concentration that was used for the primary mAb. In the controls, no specific immunolabeling was observed. All sections were also stained using conventional enzyme labeling as previously described (Otterbach et al, 2000).

\section{Microscopy and Image Processing}

Immunostained preparations were examined on a Zeiss Axioplan 2 fluorescence microscope (Carl ZeissWerke, Germany) equipped with appropriate filters. Separate images for DAPI, Cy3, and FITC staining were captured digitally from triple-stained specimens into color-separated components using an AxioCam digital camera (Carl Zeiss-Werke) and AxioVision2.05 multi-channel image processing (Carl Zeiss Vision $\mathrm{GmbH}$, Munich-Hallbergmoos, Germany). The red (for Cy3), blue (for DAPI), and green (for FITC) components were merged, and composite images were imported as JPEG files into Photolmpact 3.0 (Ulead Systems, Inc., Torrance, California) for further analysis.

\section{Breast cancer Ck 5 negative}

\section{个9\%}

myoepithelial cell 
blot sheet was incubated with the Ck5/6 mAb (Chemicon, Hofheim, Germany) diluted 1:3000 in PBS-Tween for 1 hour. Horseradish peroxidase (HRP)-conjugated antibodies to mouse IgG (DAKO) were applied for 20 minutes (diluted 1:500 in PBS-Tween). The immunoreactive polypeptide bands were detected by enhanced chemiluminescence (AmershamPharmacia Biotech, Freiburg, Germany). After exposure of x-ray films, the same PVDF membrane was rehydrated using methanol (2 seconds) and distilled water (1 minute) and subjected to a second immunoreaction using monoclonal $\mathrm{mAb}$ M20 against Ck8 (Euro-Diagnostica, Arnhem, The Netherlands). The resulting second enhanced chemiluminescence revealed both polypeptides immunoreactive for $\mathrm{Ck} 5 / 6$ and polypeptides immunoreactive for Ck8. Finally, the PVDF membrane was stained with Coomassie brilliant blue for control of complete polypeptide transfer.

\section{Acknowledgements}

This study is dedicated to Professor Gerhard Seifert and Professor Karl Lennert on the occasion of their $80^{\text {th }}$ birthdays.

The expert technical assistance of Mrs. Bettina Broemmelkamp is gratefully acknowledged. We thank Ms. Monika Dirkwinkel for preparing the schematic drawings.

\section{References}

Achtstaetter T, Hatzfeld M, Quinlan RA, Parmelee DC, and Franke WW (1986). Separation of cytokeratin polypeptides by gel electrophoretic and chromatographic techniques and their identification by immunoblotting. Methods Enzymol 134:355-371.

Allred DC and Mohsin SK (2001). Biological/features of human premalignant breast disease. In: Harris JR, Lippman ME, Morrow M, and Kent Osborne C, editors. Diseases of the breast, 2nd ed. Philadelphia: Lippincott Williams \& Wilkins, 355-366.

Anderson TJ, Ferguson DJ, and Raab GM (1982). Cell turnover in the "resting" human breast: Influence of parity, contraceptive pill, age and laterality. $\mathrm{Br} \mathrm{J}$ Cancer 46:376382.

Clarke RB, Howell A, Potten CS, and Anderson E (1997). Dissociation between steroid receptor expression and cell proliferation in the human breast. Cancer Res 57:4987-4991.

Cooper D, Schermer A, and Sun TT (1985). Classification of human epithelia and their neoplasms using monoclonal antibodies to keratins: Strategies, applications and limitations. Lab Invest 52:243-256.

Dooley WC, Ljung BM, Veronesi U, Cazzaniga M, Elledge RM, O'Shaughnessy JA, Kuerer HM, Hung DT, Khan SA, Phillips RF, Ganz PA, Euhus DM, Esserman LJ, Haffty BG, King BL, Kelley MC, Anderson MM, Schmit PJ, Clark RR, Kass FC, Anderson BO, Troyan SL, Arias RD, Quiring JN, Love SM, Page DL, and King EB (2001). Ductal lavage for detection of cellular atypia in women at high risk for breast cancer. J Natl Cancer Inst 93:1624-1632.

Dulbecco R, Allen WR, Bologna M, and Bowman M (1986). Marker evolution during the development of the rat mammary gland: Stem cells identified by markers and the role of myopithelial cells. Cancer Res 46:2449-2456.
Elston CW and Ellis IO (1989). The breast, 1st ed. Edinburgh: Harcourt Brace and Company Ltd.

Holland R, Peterse JL, Millis RR, Eusebi V, Faverly D, van de Vijver J, and Zafrani B (1994). Ductal carcinoma in situ: A proposal for a new classification. Semin Diagn Pathol 11: 167-180.

Joshi K, Smith JA, Perusinghe N, and Monoghan P (1986). Cell proliferation in the human mammary epithelium. Differential contribution of epithelial and myoepithelial cells. Am J Pathol 124:199-206.

Kelsey JL, Gammon MD, and John EM (1993). Reproductive factors and breast cancer. Epidemiol Rev 15:36-47.

Kordon EC and Smith GH (1998). An entire functional mammary gland may comprise the progeny from a single cell. Development 125:1921-1930.

Lakhani SR and O'Hare MJ (2001). The mammary myoepithelial cell-Cinderella or ugly sister. Breast Cancer Res 3:1-4.

Moll R (1998). Cytokeratins as markers of differentiation in the diagnosis of epithelial tumors. Subcell Biochem 31:205262.

Moll R, Franke WW, Schiller DL, Geiger B, and Krepler R (1982). The catalog of human cytokeratins: Patterns of expression in normal epithelia, tumors and cultured cells. Cell 31:11-24.

Nagle RB, Bocker W, Davis JR, Heid HW, Kaufmann M, Lucas DO, and Jarasch ED (1986). Characterization of breast carcinomas by two monoclonal antibodies distinguishing myoepithelial from luminal epithelial cells. J Histochem Cytochem 34:869-881.

O'Connell P, Pekkel V, Fuqua S, Osborne CK, and Allred DC (1994). Molecular genetic studies of early breast cancer evolution. Breast Cancer Res Treat 32:5-12.

Otterbach F, Bankfalvi A, Bergner S, Decker T, Krech R, and Boecker W (2000). Cytokeratin 5/6 immunohistochemistry assists the differential diagnosis of atypical proliferations of the breast. Histopathol 37:232-240.

Page DL and Anderson TJ (1987). Diagnostic histopathology of the breast, 1st ed. Edinburgh: Churchill Livingstone.

Pechoux C, Gudjonsson T, Ronnov-Jessen L, Bissell MJ, and Petersen OW (1999). Human mammary luminal epithelial cells contain progenitors to myoepithelial cells. Dev Biol 206:88-99.

Perou CM, Sorlie T, Eisen MB, van-de-Rijn M, Jeffrey SS, Rees CA, Pollack JR, Ross DT, Johnsen H, Akslen LA, Fluge O, Pergamenschikov A, Williams C, Zhu SX, Lonning PE, Borresen-Dale AL, Brown PO, and Botstein D (2000). Molecular portraits of human breast tumours. Nature 406:747-752.

Peterson OW, Nielsen HL, Gudjonsson T, Viladsen R, Ronnov-Jessen L, and Bissell MJ (2001). The plasticity of human breast carcinoma cells is more than epithelial to mesenchymal conversion. Breast Cancer Res 3:213-217.

Purkis PE, Steel JB, Mackenzie IC, Nathrath WB, Leigh IM, and Lane EB (1990). Antibody markers of basal cells in complex epithelia. J Cell Sci 97(Pt 1):39-50.

Shoker BS, Jarvis C, Clarke RB, Anderson E, Munro C, Davies MP, Sibson DR, and Sloane JP (2000). Abnormal regulation of the oestrogen receptor in benign breast lesions. J Clin Pathol 53:778-783. 
Silverstein MJ, Poller DN, Waisman JR, Colburn WJ, Barth A, Gierson ED, Lewinsky B, Gamagami P, and Slamon DJ (1995). Prognostic classification of breast ductal carcinomain-situ. Lancet 345:1154-1157.

Siziopikou KP and Schnitt SJ (2000). MIB-1 proliferation index in ductal carcinoma in situ of the breast: Relationship to the expression of the apoptosis-regulating proteins $\mathrm{bcl}-2$ and p53. Breast J 6:400-406.

Sloane JP (2001). Biopsy pathology of the breast, 2nd ed. London: Arnold.

Sonnenberg A, Daams H, Van der Valk MA, Kilkens J, and Hilgers $J$ (1986). Development of mouse mammary gland: Identification of stages in differentiation of luminal and myoepithelial cells using monoclonal antibodies and polyvalent antiserum against keratin. J Histochem Cytochem 35:1037-1046.
Taylor-Papadimitriou J, Wetzels RHW, and Ramaekers FC (1991). Intermediate filament protein expression in normal and malignant human mammary epithelial cells. In: Dickson RB and Lippmann ME, editors. Genes, oncogenes and hormones: Advances in cellular and molecular biology of breast cancer. Boston: Kluwer Academic Publishers, 355-378.

Trask DK, Band W, Zacjchowski A, Yaswen P, and Suh T (1990). Keratins as markers that distinguish normal and tumor-derived mammary epithelial cells. Proc Natl Sci USA 87:2319-2323.

Willett WC, Rockhill B, Hankinson SE, Hunter DJ, and Colditz GA (2001). Epidemiology and nongenetic causes of breast cancer. In: Harris JR, Lippman ME, Morrow M, and Kent Osborne C, editors. Diseases of the breast, 2nd ed. Philadelphia: Lippincott Williams \& Wilkins, 175-220.

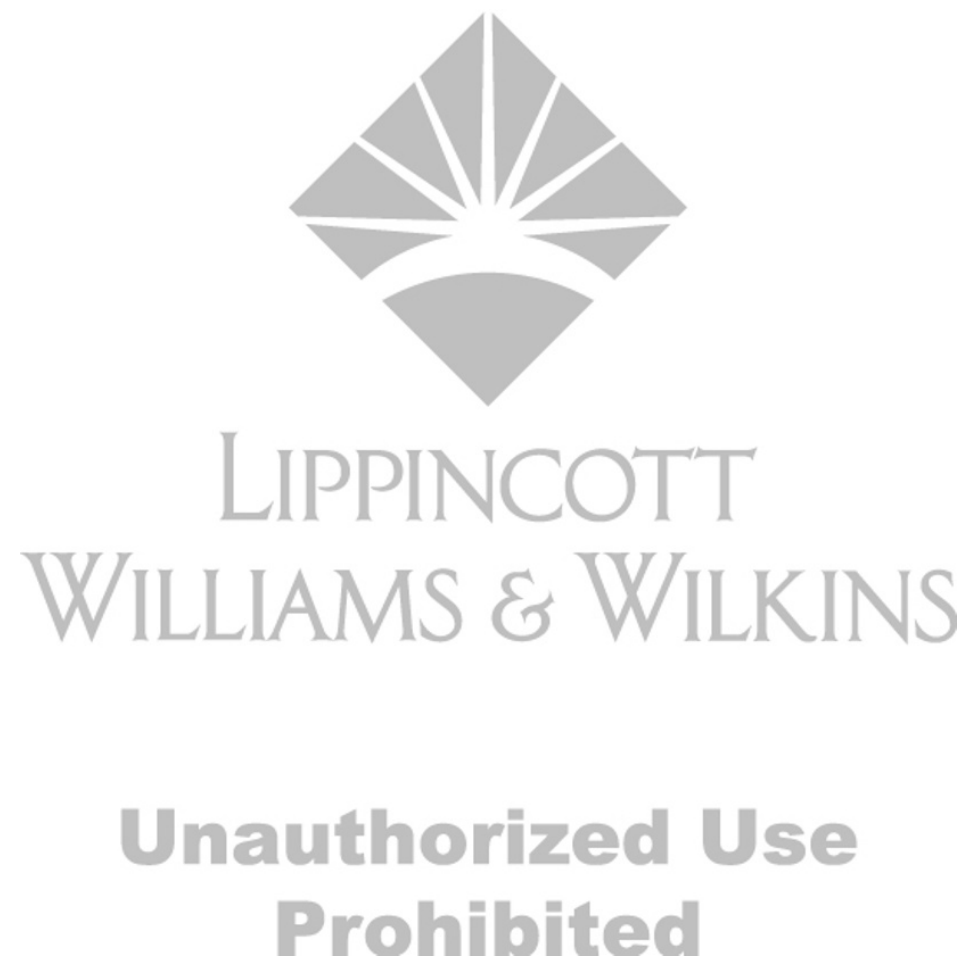

